\title{
WIREST LANG LAB: MOBILE PLATFORM LANGUAGE LABORATORY BASED ON REST WEB SERVICE
}

\author{
Henry Chong, Hantze Sudarma, Ferdinand Ariandy Luwinda, \\ Ikhtiar Faahakhododo, Ford Lumban Gaol
}

Binus University, J1. K. H. Syahdan No. 9, Palmerah, Jakarta Barat 11480, Indonesia

Received 2014-08-18; Revised 2014-11-12; Accepted 2014-12-16

\begin{abstract}
Problem statement: Language Lab plays crucial role in learning foreign language. With its capability to create environment of connecting students with students, connecting student with teacher and giving the impactful learning resources, some of institution are dare to invest of expensive system. Hence, some of them keep searching for more efficient way to learning language. In this study, based on the previous research of REST Web Service as open content, proposed a Mobile Platform Based Language Laboratory on Web Service. With this idea, hopefully, a more fun language learning mobile environment can be created in the future.
\end{abstract}

Keywords: Mobile Platform, Language Laboratory, Web Service, REST

\section{INTRODUCTION}

The development of Information and Communication Technology (ICT) play a crucial role in various section of the learning world such as enabling rapid progress of learning by using mobile platform, offering ubiquitous open learning system and connecting mobile client-side with the resources using the internet web services.

Besides, conventional language laboratory can be expensive, sometime offering limited feature and in fact need continuous equipment maintenance. Hence, for that reason, the adoption of the alternative and more affordable such as mobile platform technology is more and more considered.

Moreover, mobile platform technology adaptation solution have capability to serve ubiquitous learning environment to the students. In that point, students are free from isolation in a single room at a time. Also, current solution supported the reuse of material.

In order to couple with described feature. This publication point is the idea to maximize the functionality of mobile platform that already equipped with screen, microphone, network and headset that not yet explored deeply by researcher.
For technical reason, REST (Representational Web Service) is chosen for its capability in developing multimedia communication via the Uniform Resource Locator (URL). REST also now emerging as alternative to SOAP-based web service with better performance (Yulianto et al., 2013).

This publication will attempt to explore a possibility of creating new lifestyle of learning that aim to provide rich feature mobile device learning lab, fully customized learning style and lifelong mobile language learning.

In the end, state of the art of this research is that we propose a mobile platform language laboratory using REST Web Service that enable user to study related activity in language laboratory anytime, anywhere and with the smallest cost that possible.

\section{BACKGROUND}

Conventional language layout commonly fulfill in two conditions. The first condition is layout with student not all facing in the direction of teacher and the second is layout with all computers facing the teacher. The problem is how to draw an attention of the student, so they can learn well. For that reason, its effectiveness began to be highly criticized Corresponding Author:Henry Chong, Binus University, Jl. K. H. Syahdan No. 9, Palmerah, Jakarta Barat 11480, Indonesia 
With mobile device, drawing an attention of the student are much easier using the notification technology. When used properly, this "mobile lab" can greatly increase the effectiveness of good teacher by giving a chance for the instructor to create new content, communicate each other anytime and anywhere and interact in the learning process freely.

Under these new methodology, the conventional view of learning process such as 'remember, transfer and recall' will be transformed into 'create, discover, apply and share' or maybe could be expanded to shifted towards 'create, discover, interconnect and understand ways to apply knowledge' (Spratt et al., 2002).

This study is extended implementation version of previous publication "ULa Lab: Ubiquitous Open Contents Web-Based Language Laboratory using REST Protocol Web Service" in mobile platform technologies (Chong and Gaol, 2013).

\section{METHODOLOGY}

To make the research can be done with a focused, clear and efficient, this systematic methodology (Fig.1) needs to be used:

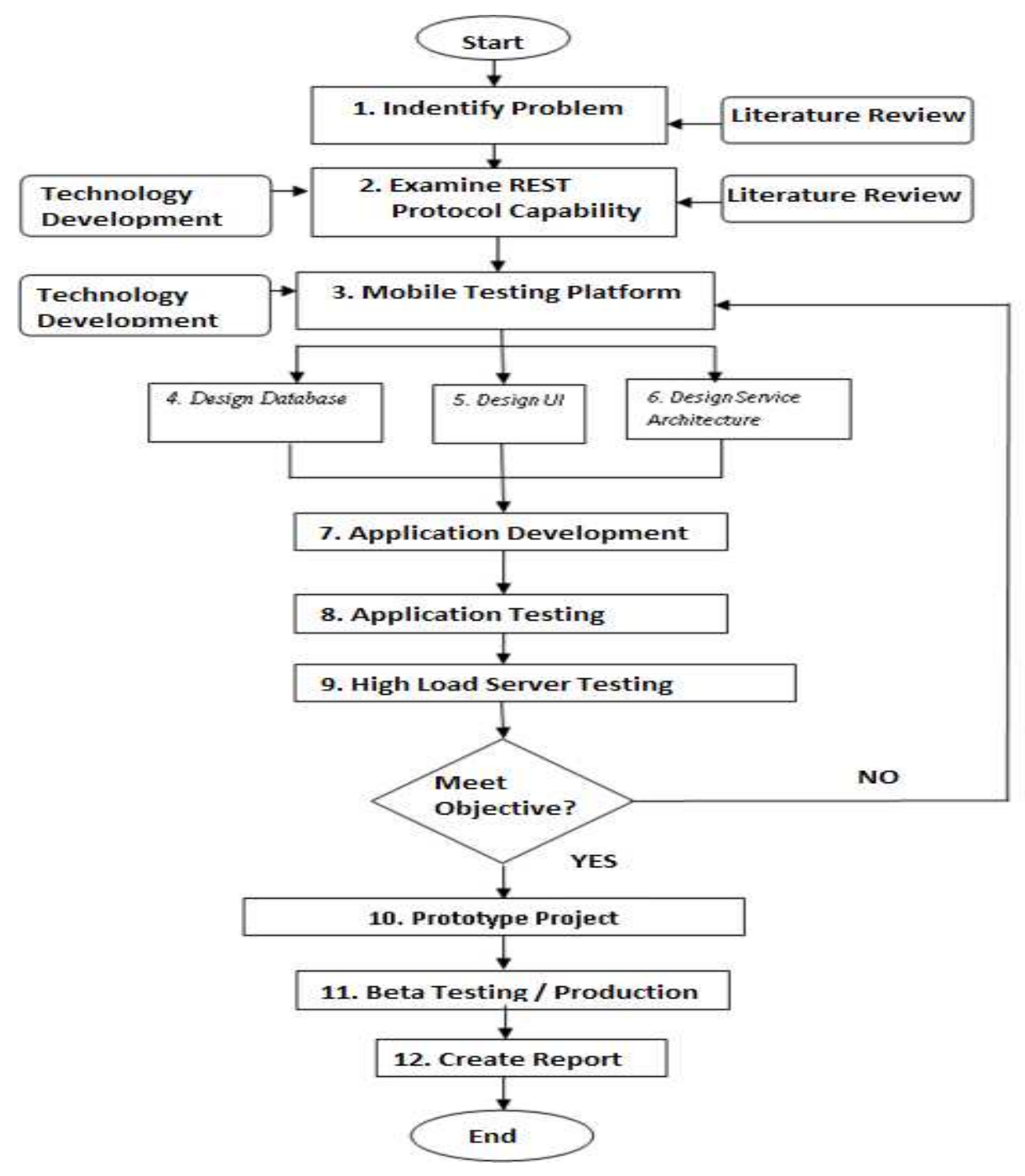

Fig. 1. Systematic Method 


\section{PROPOSED RESEARCH}

The language laboratory provided in this research contain 3 simple menu, such as:

\subsection{Communicate}

In learning language, participation in communication is very important. In short, practice make perfect. To couple that, a new teaching model is needed (Patel, 2013).

In this momentum of rapid development in information technology, this research offered a better pattern, which it called as Mobile Learning Laboratory. In the industrial ready scenario, "Communication skill" has been growing its prominence (Tiono, 2001).

This menu (Fig. 2) intended to create a communicative area for student-teacher, student-student and teacher-teacher. In this prototype android apps, text conversation is provide. But, in future, as long as the technology development increased, the research suggested a video call. This will prevent students to feel bored whey they study in the language laboratory with their monotonous activities there.

With this menu, teacher can kept their private email, ym, skype id, secured while the communication still can be provided.

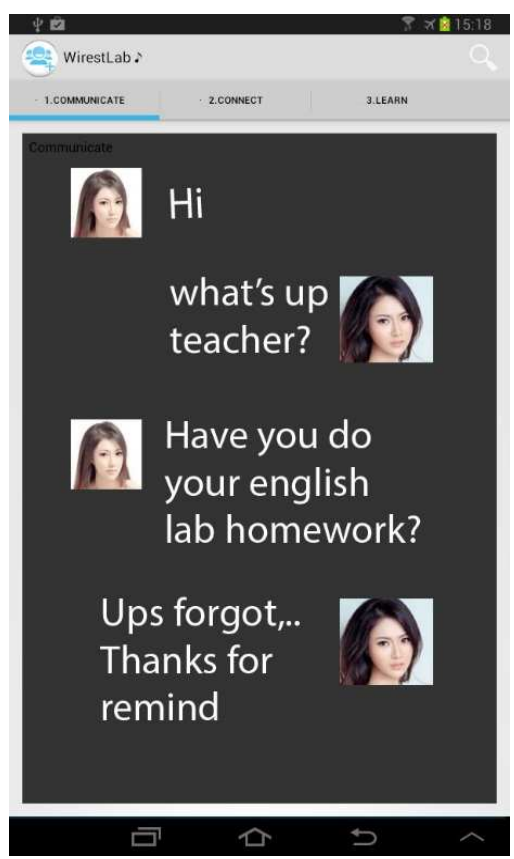

Fig. 2. Communicate menu

\subsection{Connection}

The method of "the talk and chalk", very popular in long history of language teaching. From the first time people live, they have to start to learn how to say "Pa Pa" and "Ma Ma". Hence, to speed up the process of learning, communication is very important. But, in this menu (Fig. 3) we are focusing in how they interact each others.

This apps intended to create a virtual classroom, but the great feature offered is "huge classroom". In this prototype research provided a text based chatting. But, in the future, video conference is suggested. Of course with capability to control which student could talk, which student just able to hear?

With this method, learning is no more limited with location and time. What the apps provide is community of learning in global class mobile environment. In this menu, they have more capability to express their ideas and argument better than classroom based environment. Because creativity is habit which come from the freedom of speaking (Sternberg, 2006)

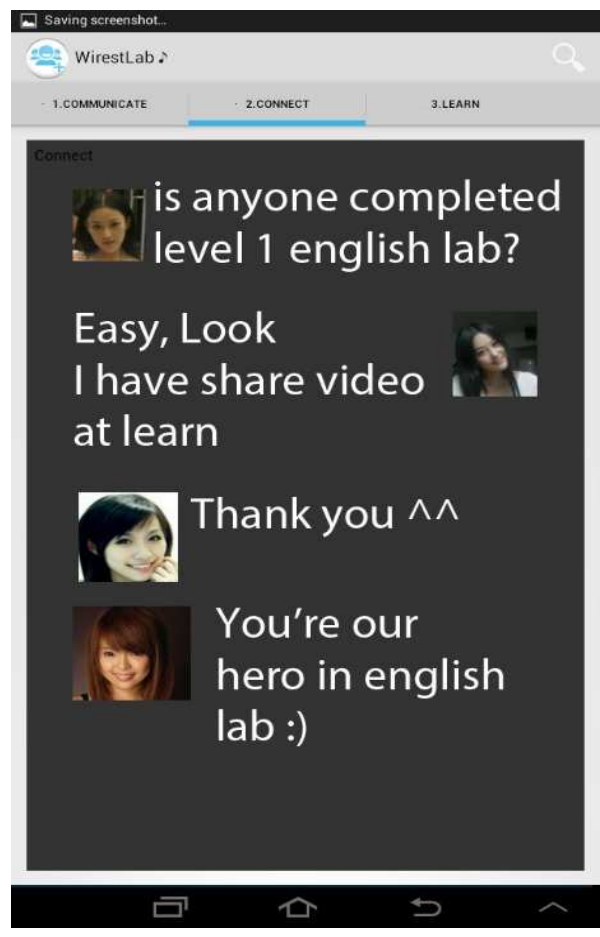

Fig. 3. Connection menu 


\subsection{Learn}

Using mobile device to provide a content to teach language has its unique advantages. It could provide content from TV, CDRom, Articles, Blogs (Betts and Glogoff, 2004) PowerPoint and Youtube Video. Combined with REST Web service infrastructure, the apps could have capability to facilitate content resources to enhance the skill of the students

Several study state that blogs can effectively facilitate language teaching and learning (Ahluwalia et al., 2011). But, the problem is, not every language laboratory has its capability to connect to the internet. With this apps and 3G connection from mobile device, learning from this resources and circumstances is no more obstacle.

Student can use the capability of video streaming Deng et al., 2010 (Fig. 4), listening to oral audio, personal speech by using mobile microphone, secured content using password and username and augmented reality content (Kose et al., 2013),

Research also suggest that educator help motivate students by using materials and implementation activities. It is not all about how high-tech the technology, but how effective this technology reaches people who don't understand technology. Especially in the importance of listening method (Razmjou and Ghazi, 2013).

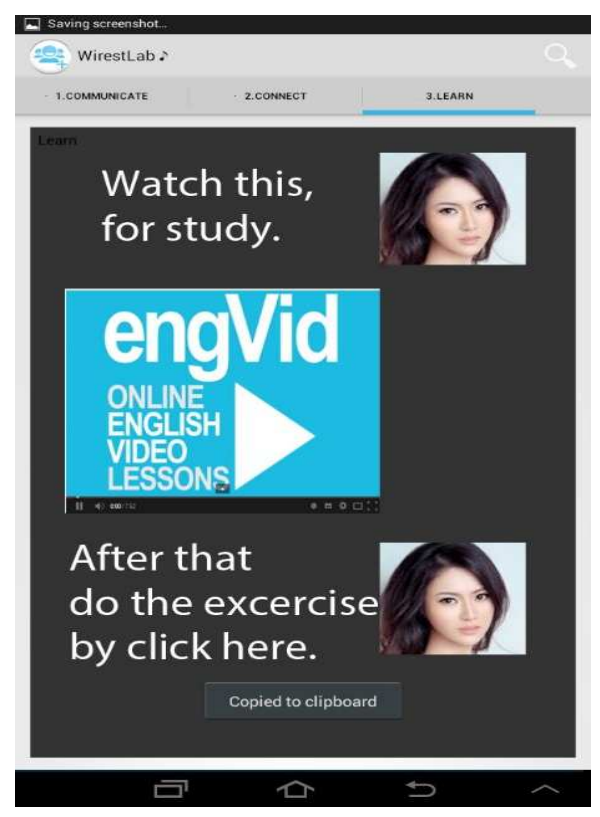

Fig. 4. Learn menu

\section{CONCLUSION}

In this publication, the researcher has made attempt to propose a new perspective of learning language. The publication is based on previous publication of research "ULa Lab open contents web-based language laboratory using REST Protocol Web Service". With this kind of learning method, hopefully, ubiquitous learning environment can be provided.

The contributions of the publication can be summarized as follows:

- This study developed an idea of implementing REST Web Service to Language Laboratory Section on mobile application using the systematic methodology founded while researching process

- This study provide the result of research and implementation of REST Web Service

- This study intended to increase curiosity in using REST Protocol in Language Laboratory Education Section

- This study provide idea to create more efficient way to learning language which in this case make learning language more fun

Our research shows that the RESTFul web services can be quite flexible and more attention should be paid for this topic in our future.

\section{ACKNOWLEDGEMENT}

The authors would like to thank their partners in the project and acknowledge the financial support given to this research by the Bina Nusantara University.

\section{ADDITIONAL INFORMATION}

\subsection{Funding Information}

Bina Nusantara University

\subsection{Author's Contributions}

Henry Chong: Main Researcher, doing study literature, code and implementation.

Hantze Sudarma: Provide idea of using REST web services.

Ferdinand Ariandy Luwinda: Supporting.

Ikhtiar Faahakhododo: Supporting.

Ford Lumban Gaol: Recommend place of submit and journal referring. 


\subsection{Ethics}

I acknowledge any ethical issue after the publication of this manuscript.

\section{REFERENCES}

Ahluwalia, G., D. Gupta and D. Aggarwal, 2011. The use of blogs in English language learning: A study of student perceptions. Profile, 13: 29-41.

Betts, J. D. and S. J. Glogoff, 2004. Instructional models for using weblogs in e-learning: A case study from a virtual and hybrid course. Sylabbus, University of Arizona.

Chong, H. and F.L. Gaol, 2013. ULa Lab: Ubiquitous Open Contents Web-Based Language Laboratory using REST Protocol Web Service. Int. J. Multimed. Ubiquitous Eng., 8: 199-205.

Deng, J., J. Hu and A.C.M. Liu, 2010. Virtualization, application streaming and private cloud computing in a training laboratory. J. Software, 5: 1306-1313.

Kose, U., D. Koc and S.A. Yucesoy, 2013. An augmented reality based mobile software to support learning experiences in computer science courses. Proc. Comput. Sci., 25: 370-374.

DOI: $10.1016 / j$.procs.2013.11.045
Spratt, M., G. Humphreys and V. Chan, 2002. Autonomy and motivation: which comes first? Lang. Teach. Res., 6: 245-266. DOI: 10.1191/1362168802Ir106oa

Patel, C.M., 2013. Enhancing communication skills through Elcs labs of GTU affiliated engineering colleges in Gujarat: An analysis. Ind. Stream Res. J., 3: 1-3. DOI: $10.9780 / 22307850$

Razmjou, L. and J.A. Ghazi, 2013. Listening practice influence on the use of communication strategies in oral transition. Theory Practice Lang. Stud., 3: 1645-1650. DOI:10.4304/tpls.3.9.1645-1650

Sternberg, R.J., 2006. Creativity is a habit. Edu. Week, 25: 47-64.

Tiono, N., 2001. Communicative listening in the language laboratory. Petra Christian University.

Yulianto, B., M. Shodiq and L.C. Dewi, 2013. Sound and digital classroom: Smart way to have language laboratory. J. Comp. Sci., 